
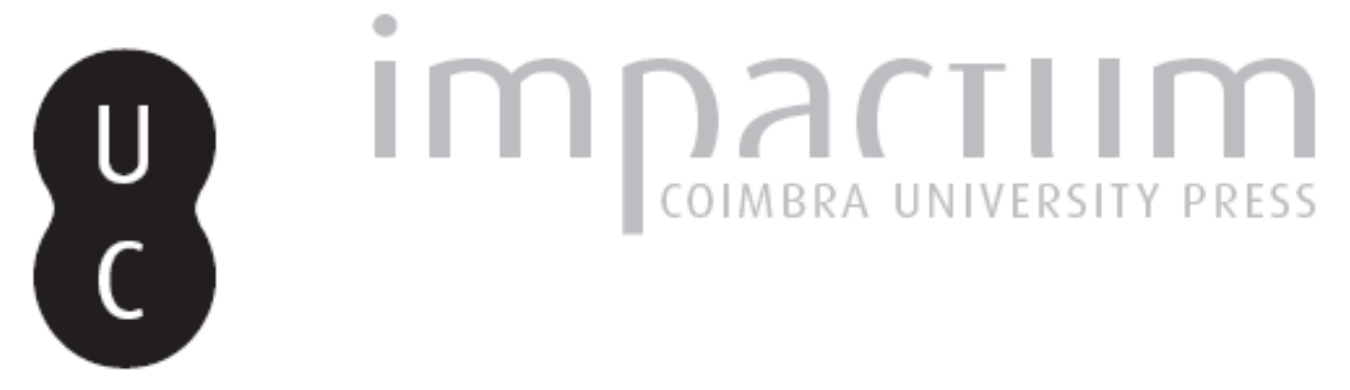

\title{
Os intelectuais e o feminismo
}

\section{Autor(es): $\quad$ Castro, Zília Osório de}

Publicado por: Imprensa da Universidade de Coimbra

URL persistente:

URl:http://hdl.handle.net/10316.2/43726

DOI:

DOI:https://doi.org/10.14195/2183-8925_24_13

Accessed : $\quad$ 26-Apr-2023 11:06:16

A navegação consulta e descarregamento dos títulos inseridos nas Bibliotecas Digitais UC Digitalis, UC Pombalina e UC Impactum, pressupõem a aceitação plena e sem reservas dos Termos e Condições de Uso destas Bibliotecas Digitais, disponíveis em https://digitalis.uc.pt/pt-pt/termos.

Conforme exposto nos referidos Termos e Condições de Uso, o descarregamento de títulos de acesso restrito requer uma licença válida de autorização devendo o utilizador aceder ao(s) documento(s) a partir de um endereço de IP da instituição detentora da supramencionada licença.

Ao utilizador é apenas permitido o descarregamento para uso pessoal, pelo que o emprego do(s) título(s) descarregado(s) para outro fim, designadamente comercial, carece de autorização do respetivo autor ou editor da obra.

Na medida em que todas as obras da UC Digitalis se encontram protegidas pelo Código do Direito de Autor e Direitos Conexos e demais legislação aplicável, toda a cópia, parcial ou total, deste documento, nos casos em que é legalmente admitida, deverá conter ou fazer-se acompanhar por este aviso. 

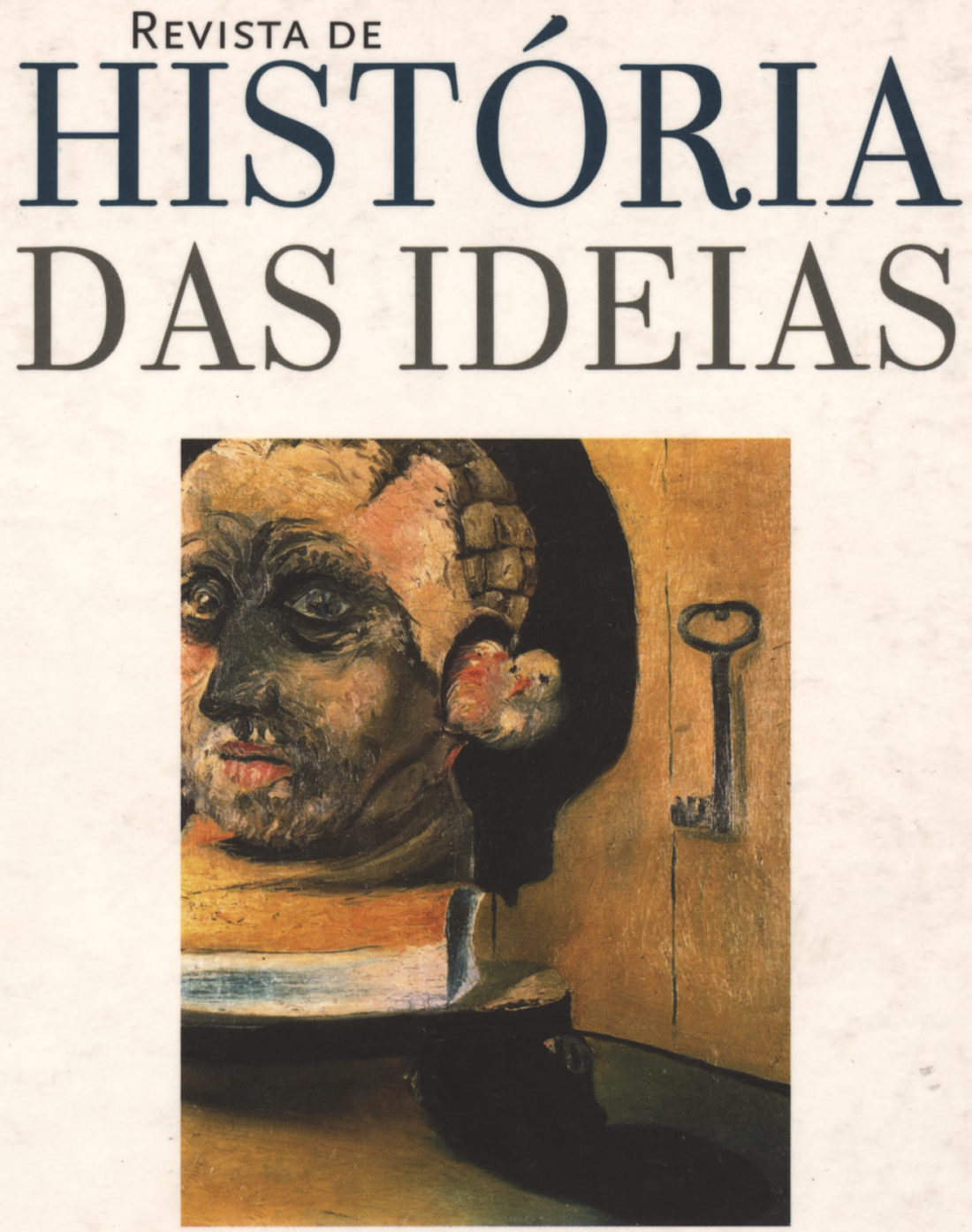

OS INTELECTUAIS E OS PODERES

Volume 24, 2003

INSTITUTO DE HISTÓRIA E TEORIA DAS IDEIAS

Faculdade de Letras da Universidade de Coimbra 


\section{OS INTELECTUAIS E O FEMINISMO}

O termo - intelectual - conhecido e usado habitualmente como adjectivo, com o Caso Dreyfus, passou a ser vulgarizado como sintagma nominal e, como tal, iniciou um longo percurso nos meios culturais que chegou aos nossos dias. O ponto de partida para esta generalização ficou a dever-se a Georges Clemenceau e a Maurice Barrrés que, embora ideologicamente distanciados, a empregaram num período mediado apenas por duas semanas de intervalo(1). O primeiro, director do periódico L'Aurore, utilizou-o em 14 de Janeiro de 1898, quando se referiu aos "escritores, artistas, universitários e cientistas" que se associaram ao protesto de Zola contra a condenação de Dreyfus. O segundo, seguiu-o, empregando o termo num artigo publicado em Le Journal, a 1 de Fevereiro de 1898. Aquele integrou-o no processo de reabilitação de um inocente. Este conferiu-lhe o sentido pejorativo de inimigo da pátria. Um associava-o a princípios universais que importava defender. O outro encarava-o à luz dos valores nacionalistas que não podiam ser ignorados.

Isto significa que conceptualmente o termo ultrapassava as barreiras ideológicas que distinguiam dois modos de pensar e do agir correspondente, para definir o pensar e o agir em si mesmo. Ou seja, os intelectuais,

* Faculdade de Ciências Sociais e Humanas da Universidade Nova de Lisboa.

(1) Sobre este assunto, veja-se Luís Crespo de Andrade, "O substantivo intelectuais", Dreyfus e a responsabilidade intelectual, Cadernos de Cultura 2, Lisboa, Centro de História da Cultura/Unl, 1999, pp. 23-41, assim como a bibliografia apresentada. E ainda Norberto Bobbio, O Filósofo e a Política, Antologia, Rio de Janeiro, Confronto, 2003, pp. 431-492. 
tendo como referentes valores diferentes, quiçá antagónicos, encontravam na primazia do pensamento concretizado no modo de agir, o ponto comum que os identificavam como tais ${ }^{(2)}$. Por outras palavras. Ser intelectual não significava pertencer a determinado quadrante ideológico, mas sim que os respectivos valores referenciais se integravam na primazia do pensamento, informando a vivência, ou seja, a vida que se vivia. Sendo assim, os intelectuais representariam a consciência da sociedade, despertando os cidadãos para valores e princípios que, estando para além da mera estratégia e prática política, era relevante manter e inculcar como legitimadores de uma e da outra. Na sua génese, caminhavam longe dos trilhos do pragmatismo político e do positivismo jurídico. Consideravam-se expoentes e arautos de uma moral cívica e independente, de cariz secular ou laica, e faziam da crítica a sua arma por excelência.

Quando o temporal e a temporalidade de raízes iluministas ocuparam o lugar da eternidade (embora sem necessariamente a negar), os intelectuais adquiriram consciência do papel que lhes cabia enquanto sucessores da sacralidade do magistério do catolicismo exercido durante séculos. $\mathrm{O}$ espaço do aqui e do agora pertencia-lhes, e era aqui e agora que tinham como missão intervir, com o proselitismo das ideias e dos ideais que veiculavam. Neste sentido, pode dizer-se que a sua função substituiu a do clérigo, enquanto portadores de uma mensagem para os seres humanos cidadãos e não, exclusivamente, para os seres humanos cristãos, e que haviam encontrado na Declaração dos Direitos do Homem e do Cidadão, de 1789, os princípios legitimadores da sua intervenção. $\mathrm{Na}$ cidade do tempo, o lugar do cidadão prevalecia sobre o do cristão, a cultura sobre a religião, o saber sobre a oração. Nesta cidade do tempo, os intelectuais, como homens de cultura, de pensamento, prestigiados pelo seu saber, formadores da opinião pública e críticos da acção governativa ocupavam tendencialmente um lugar ímpar. Face ao poder político perfilava-se o poder cultural, face à sociedade política erguia-se a sociedade civil. A emergência dos intelectuais configurava, portanto, o surgimento de um contra-poder.

(2) Veja-se Maria João Cabrita, "Os intelectuais e a política na viragem do século", in Dreyfus e a responsabilidade intelectual, Cadernos de Cultura 2, cit., pp. 53-60. 
Um dos seus objectivos era formar "uma opinião pública esclarecida e crítica"(3), servindo-se para este fim de publicações periódicas, nomeadamente de revistas, que pelas suas características de periodicidade e distribuição eram consideradas veículos difusores por excelência das ideias e dos conhecimentos mais actuais. Para que estes chegassem a um número cada vez mais alargado de leitores era imprescindível implementar a instrução desde o nível mais elementar - ler e escrever - ao mais aprofundado - o universitário. A educação daria as mãos à instrução em todos os seus graus, promovendo em comum o desenvolvimento cultural, o hábito de pensar e de reflectir, e ao mesmo tempo, criando o espaço da crítica. Neste contexto, o empenho dos intelectuais na fundação de universidades populares, da promoção de estudos livres e da criação de revistas culturais ${ }^{(4)}$ não só é compreensível como consequente. Mediante o empenhamento dos intelectuais, a sociedade civil criou os seus próprios órgãos de intervenção, independentes do poder político e veiculadores de outros projectos de sociedade, pela proposta de outras formas de ser e de estar, e pela "descoberta" de valores esquecidos, subvalorizados ou ignorados, para além da "criação" ou implementação de formas de pensar inovadoras.

Entre os aspectos que, na sequência do movimento intelectual iniciado em França, interessaram os intelectuais portugueses, contava-se o da situação da mulher em Portugal. Estava-se já na década de trinta quando aqui se criaram algumas revistas que pelo seu conteúdo se apresentavam como uma alternativa à política que se seguira à queda da $1^{\mathrm{a}}$ República e se iria configurar no Estado Novo. Entre elas salientavam-se pelo interesse manifesto pela "questão feminina", a Pensamento, O Diabo e $O$ Sol Nascente, como já se teve ocasião de referir ${ }^{(5)}$. Todas aludem com incidências e implicações diversificadas a feministas e ao feminismo, donde decorre o carácter plurívoco da abordagem. Só o facto desta temática ser tratada em publicações que, pela via cultural, propunha mudanças sociopolíticas e que procurava preparar a opinião pública - os seus

(3) Luís Crespo de Andrade, cit., p. 31.

(4) Veja-se, por exemplo, Revistas. Ideias e Cultura, Lisboa, Livros Horizonte, 2002.

(5) Veja-se Zília Osório de Castro, "Paridade Cultural", in Falar de Mulheres. Da Igualdade à Paridade, Lisboa, Livros Horizonte, 2003, pp. 279-294. 
leitores - para elas, revela sensibilidade à problemática do lugar da mulher na sociedade que se pretendia construir.

O primeiro ponto elucidativo pelo seu significado consiste no facto de ter sido proporcionado às mulheres uma tribuna em revistas de colaboração maioritariamente masculina. Depois salienta-se o reconhecimento das suas potencialidades e da possibilidade da sua comparticipação na criação da nova sociedade. Por último, e implícita nestas duas, assinala-se a consciencialização de uma outra ideia de mulher, presente numa outra imagem - a da mulher perspectivada na sua dignidade de ser humano, com direitos e com deveres, com intervenção na sociedade em que vive, e assumindo aí as responsabilidades daí decorrentes.

Parece evidente que os intelectuais aceitaram e promoveram, pelo menos tendencialmente, a proposta de intervenção cívica da mulher - a mulher estava na sociedade e, com o homem, contribuía para a sua construção que, no caso concreto, seria ditada pela inovação. Estas mulheres, porque tinham despertado para si mesmas, tinham consciência desta realidade e do papel cívico que lhes cabia. Aliavam, assim, a participação cívica ao sufragismo das feministas republicanas, identificado como uma forma de intervenção política, dando origem a um outro feminismo - o feminismo interventivo, e não apenas participativo, um feminismo cívico e não apenas político. A mulher afirmava-se como tal na realidade civil do dia a dia - nas funções que partilhava, nas profissões que exercia. O apelo à educação, que marcara os finais do século XIX e os inícios do século XX, dava agora os seus frutos, concretizados nas crescentes habilitações científicas femininas que, não só prestigiavam a mulher como intelectual, como lhe facultavam o lugar a que tinha jus na cidade.

O feminismo intelectual e de participação dos anos trinta completou com a sua quota parte o feminismo político de intervenção. Ambos resultavam de um certo feminismo individual de afirmação que estudos recentes $^{(6)}$ fazem remontar a inícios de oitocentos, revelando aspectos diferentes de um movimento único - o movimento em prol da dignificação da mulher como ser humano, com os direitos que lhe são inerentes

(6) Veja-se comunicação de Maria Emilia Stone intitulada Mulheres desconhecidas da História e da Historiografia e apresentada no $2^{\circ}$ Curso Livre de Estudos sobre a Mulher, organizado por Faces de Eva. Centro de Estudos sobre a Mulher em Maio de 2003, na Faculdade de Ciências Sociais e Humanas, da UNL, (a publicar nas respectivas Actas). 
e a consequente libertação de anomalias que ao longo dos tempos a tinham acompanhado na vida pessoal, social, política, etc. Esta mutação de índole revolucionária, pois consubstanciava uma ruptura com o existente, pressupondo uma mudança de mentalidades, processou-se no tempo longo braudeliano, vencendo dificuldades e contando como vitórias as etapas vencidas e ultrapassadas. Foi um processo lento, mas que acompanhou - diríamos naturalmente - o processo histórico do despertar da contemporaneidade ao seguir a passo e passo a concretização da matriz iluminista quanto ao carácter teleológico do devir dos seres humanos, à sua maioridade vocacional e aos ideais de liberdade e felicidade enquanto quota parte essencial da vida vivida.

Encontra-se em Ana de Castro Osório um testemunho de quem sentiu e viveu o que se acaba de afirmar. Nos inícios do século XX, traçou o quadro desta evolução em palavras que pela sua precisão e objectividade exponenciam conhecimento profundo e assumido da situação que inexoravelmente iria conduzir ao reconhecimento dos direitos da mulher enquanto expoentes da sua dignidade humana e, portanto, ao caminho da maioridade. Se bem que nunca tivesse abandonado ou minimizado o papel de paladina da intervenção política, não deixou de optar igualmente pela participação cívica. Em 1905, escrevia em livro dedicado Às Mulheres Portuguesas:

"Feminismo [...]. É ainda em Portugal uma palavra de que os homens se riem ou se indignam $[\ldots]$ e de que a maioria das mulheres cora [...]. E no entanto, nada mais justo, nada mais razoável do que este caminhar seguro, embora lento, do espírito feminino para a sua autonomia. O homem português não está habituado a deparar no caminho da vida com as mulheres suas iguais pela ilustração, suas companheiras pelo trabalho, suas colegas na vida pública. Por isso as desconhecem, as desprezam, por vezes, as temem quase sempre"( $)$.

Neste texto, Ana de Castro Osório expõe os princípios básicos do feminismo cultural perfilhado na década de trinta pelos intelectuais portugueses. Sem negar a inevitabilidade da luta, traduzida no caminhar lento e seguro, sem esquecer as opressões, presentes na alusão ao desconhecimento, ao desprezo e ao temor, subvalorizou os aspectos

(7) Ana de Castro Osório, Às Mulheres Portuguesas, Lisboa, 1905, pp. 12-11. 
sociais e políticos do feminismo. Sem os ignorar - falou no trabalho e na vida pública - colocou-os sim na dependência das conquistas do espírito. Para ocupar na sociedade o lugar que lhe pertencia, para adquirir a autonomia desejada, a mulher tinha de desenvolver as suas capacidades intelectuais, já que cientificamente estava provado que, neste campo, em nada era inferior ao homem. A maioridade kantiana estava ao seu alcance. E ela atingia-se pela ilustração, pela educação e pela aplicação dos conhecimentos adquiridos na vida do dia a dia. Tornava-se, assim, senhora de si mesma e capaz de se afirmar como tal. A valorização começava por ser uma proposta individual que se reflectia depois social e politicamente. $\mathrm{O}$ feminismo de Ana de Castro Osório manifestava-se, portanto, em duas vertentes e baseava-se numa aposta sem hesitações nem reservas nas potencialidades femininas. Entre as mulheres havia sem dúvida capacidades diferentes, tal como as havia entre os homens, mas todas elas eram "educáveis [...] melhoráveis [...] úteis, laboriosas e conscientes obreiras, ajudando à melhoria da grande colmeia social"(8).

No seu entender, ser feminista implicava em primeiro lugar declarar guerra de morte à ignorância e à inactividade, em nome de um ideal que passava pela realização de cada mulher e que era, ao mesmo tempo, sinal da sua libertação. A mulher "só no trabalho pode encontrar a sua carta de alforria, não no trabalho esmagador exercido como um castigo, mas no trabalho que enobrece o espírito, que dá o belo orgulho dos que contam consigo e nunca foram um peso para ninguém"(9). Cada mulher era obreira do seu próprio destino, enquanto construtora da sua personalidade. Fazê-la depender, assim como ao lugar que ocupava na sociedade, apenas das leis ou de factores imprevisíveis, traduzia uma inferioridade inconciliável com a sua existência de ser humano e, além disso, mantinha a submissão secular. Responsabilizar a mulher pelo próprio destino era o objectivo do feminismo em análise, que correspondia ao feminismo pessoal acima mencionado. Pressupunha uma crença profunda nas suas potencialidades, a rejeição de "fenómenos" ou de "monstros femininos" e o apelo sem reservas às potencialidades de cada uma:
(8) Idem, p. 15.
(9) Idem, p. 21. 
"Ser feminista não é querer as mulheres umas insexuais, umas masculinas de caricatura [...] é sim desejá-las criaturas de inteligência e de razão, educadas útil e praticamente de modo a verem-se a abrigo de qualquer dependência, sempre amarfanhante para a dignidade humana"(10).

Neste contexto, a valorização da mulher, acima considerada como aspecto fundamental do feminismo, identificava-se com a noção de dignidade humana. Tanto o homem como a mulher participavam da qualidade de seres humanos e eram dotados de idênticas capacidades. Integrada nesta perspectiva, a reivindicação da igualdade carecia de sentido enquanto objectivo exclusivo dos movimentos feministas, já que a todos os seres humanos pertencia como direito próprio a possibilidade de desenvolverem todas as sua potencialidades, quaisquer que elas fossem. E o feminismo justificava-se, tão só, por exigir para a mulher o que já fora reconhecido ao homem, isto é, o feminismo consciente definia-se como "aquele em que a mulher trabalha, pensa e actua autonomamente, lutando pela vida como o homem nas mesmas condições"(11). Enquanto expressão de libertação, implicava justamente "julgar todos os indivíduos intelectualmente semelhantes, sem distinção de sexo, aptos igualmente a estudar e a progredir pelo trabalho"(12). Mas, como movimento em prol da liberdade feminina não prescindia dos meios para tornar efectiva esta dupla vertente. Daqui decorria o sentido da política de educação desenvolvida por Ana de Castro Osório, como primordial ao feminismo, e também pensada simultaneamente nas suas implicações individuais e sociais.

Se bem que Ana de Castro Osório possa ser considerada a precursora do feminismo cultural perfilhado nos aos trinta, não se pode afirmar que este não tivesse trazido nada de novo. O empenhamento na educação como forma de valorização pessoal indispensável cedeu lugar à consciência de que a mutação social e política dependia da intervenção cultural e para esta também as mulheres se sentiam chamadas. Isto significa que o feminismo de cariz cultural manteve a sua actualidade embora com incidência díspar. Partilhou, deste modo, embora em grau diferente, a aposta nas virtualidades da intervenção dos intelectuais na sociedade.

\footnotetext{
(10) Idem, p. 24.

(11) Idem, As operárias das fábricas de Setúbal e a greve, Sociedade Portugusa do jornal "O Radical", 1911, p. 18.

(12) Idem, p. 18.
} 
Esse período assistiu, de facto, à formação de uma nova vaga feminista e à consciencialização da função social e política dos intelectuais. Movimentos aparentemente distanciados nas suas finalidades integraram um projecto comum, no qual latejavam propostas alternativas de sociedade e de relações sociais. Nomes hoje incontornáveis na história do feminismo em Portugal como o de Elina Guimarães, Adelaide Cabete, Angelina Vidal, Cândida Pinto, Clara Ferreira Alves, Maria Lamas, ao lado de outras cuja memória se perdeu como Leopoldina Mesquita, Alsácia Santos Machado, Dinah Santos Silva, Maria O'Neil, entre tantas outras, formaram um grupo de mulheres notáveis pelo seu empenhamento, intervenção e afirmação. Por outro lado, todas elas se distinguiram pela presença em publicações periódicas relevantes pelo que representavam de alternativa e inovação, tais como as atrás referidas, e que marcaram o panorama cultural português como expoentes da responsabilização dos intelectuais femininos e masculinos na reforma da sociedade do presente e na construção da cidade do futuro. Ali, a parceria feminina, embora em "tempo de alvorada", não se apresentava, por isso, de menor importância, e emergia como uma promessa de evidente intencionalidade.

Nessa cidade, as mulheres estavam visivelmente presentes, assim como o estavam nas páginas desses periódicos. Não foi por acaso que a Pensamento publicou nos números iniciais uma série de artigos sobre o feminismo e ao longo dos anos abrigou nas suas páginas artigos científicos e de opinião, além da tradicional colaboração literária, em que pontuavam temas sociais, cuja autoria evidencia nítida aposta na colaboração feminina e da relevância que ali the era atribuída. $O$ Diabo partilhava idêntica sensibilidade, pois não terá sido igualmente por acaso que não só promoveu um Inquérito às Mulheres Portuguesas, cujas respostas acompanhadas das fotografias das entrevistadas inseriu em números sucessivos, como procurou sondar diversos quadrantes sociais sobre os assuntos que considerou pertinentes. Incidindo estes sobre o desenvolvimento intelectual da mulher e o seu papel social, o trabalho e as aspirações femininas, $o$ amor, a maternidade, $o$ pacifismo e a felicidade traduziam o reconhecimento de que as mulheres tinham uma palavra a dizer sobre si próprias e sobre a sua condição social e económica, enquanto que a questão da intervenção política não foi sequer abordada. Além das respostas ao Inquérito, a colaboração feminina era diminuta, excepto no respeitante ao âmbito literário, onde Alice Ogando ocupou lugar de destaque. Curiosamente, artigos sobre feminismo ou questões afins saíram 
da pena masculina. Apesar de tudo, a emergência da mulher não deixa dúvidas, tal como não as deixa a orientação editorial da Pensamento.

Indo mais além na análise feminista dos dois periódicos, verifica-se que fundamentalmente partilhavam concepções idênticas. As mulheres, como seres humanos que eram, constituíam parte integrante da sociedade com a especificidade própria da natureza, assumida tanto fisiológica como culturalmente. Pelo facto de se situarem no mesmo espaço e no mesmo tempo - tempo e espaço das duas publicações que as acolhiam entre o número dos seus colaboradores - participavam num projecto comum que envolvia a sociedade na totalidade convergente dos seus membros. Rejeitavam tanto o confronto como o mimetismo, embora reconhecessem as diferenças que histórica e culturalmente se tinham instalado, subvertendo a igualdade ingénita de todos os seres humanos. A cidade nova que desejavam, seria fruto da acção de mulheres e de homens e, portanto, seria património comum. Por isso, embora conjunturalmente se justificassem dinâmicas específicas (leia-se feministas), elas só encontravam legitimação no âmbito de um projecto comum que visasse a plenitude efectiva da dignidade humana. Seria este o papel dos movimentos e das publicações feministas que, fugindo da exclusividade do gheto, não deixavam de assumir uma identidade própria num movimento comum. A mensagem tanto da Pensamento como de $O$ Diabo seria, consequentemente, a seguinte: também às mulheres, como intelectuais, cabia um papel na construção da cidade nova e este implicava, igualmente, a génese da mulher nova.

Seria esta a dupla intenção da Pensamento ao escolher um grupo de mulheres para lhes entregar a redacção de uma série de artigos sobre $o$ feminismo, como acima se referiu. No entender dos editores, havia um combate a travar e os combatentes teriam de ser primordialmente as mulheres. Importava que a emergência da mulher nova na sociedade resultasse, simultaneamente, de uma reflexão e de uma projecção. Implicava, por consequência, que o feminismo se identificasse como um movimento cultural, entendido não só sob o ponto de vista das concepções formuladas, como ainda dos seus reflexos nas acções concretas. Implicava, portanto, a reformulação do modo de pensar e de agir, numa cruzada que, segundo a Pensamento cabia às mulheres, como meio de conquista da dignidade humana a que tinham jus. Só assim conquistariam o lugar que lhes era próprio na sociedade a que pertenciam, atingindo a maioridade pessoal e social. 
Se o feminismo veiculado pela Pensamento resultava implícita e formalmente dos pressupostos acabados de referir, tornava-se explícito através dos textos publicados sobre o assunto, identificando a mensagem da revista e as mensagens das respectivas autoras. Assim, também elas apontavam para a cidade nova construída com o contributo das mulheres, pois que, como dizia Maria O'Neil, "uma sociedade melhor nunca se poderá obter sem que a mulher se dignifique pelo trabalho, pelo vestuário, pelos costumes, e dando ao seu querer uma directriz definida, se não esqueça que tem o seu lugar no lar e na colectividade, e pode, como o homem pensar e agir, e sendo este o seu melhor amigo e colaborador, combinarem os esforços para obterem uma sociedade melhor onde a felicidade não seja, como hoje, um mito"(13).

O apelo à igualdade essencial dos seres humanos definida em termos de pensar e agir, implicava o da aceitação do papel da mulher enquanto "colaboradora sincera, desinteressada e leal do homem"(14) e do seu contributo para o bem familiar e para o bem comum. E exigia que a mulher desenvolvesse as suas "faculdades intelectuais e morais" e reivindicasse o direito de "lutar pela realização humana, de aspirar a novas condições de vida que lhe permitissem possuir uma personalidade bem definida [...], de repudiar a condição inferior de satélite e de aspirar à categoria de planeta ou de estrela - tal como os homens - segundo os dotes de inteligência, as faculdades de trabalho e as qualidades morais que as caracterizam"(15).

Nas páginas da Pensamento e pela pena das suas colaboradoras, a mulher reivindicava uma função social, além da revisão da sua situação familiar, profissional e até política (direito de voto). Sendo qualquer delas delimitativas da sua realização como ser humano, só eliminando os obstáculos atávicos que a condicionavam em cada um dos aspectos, ela seria senhora da sua personalidade. Ora, para a mulher, tal como para o homem, consegui-lo implicava o reconhecimento de duas prerrogativas - liberdade de pensamento e liberdade de acção ${ }^{(16)}$. A primeira permitia-lhe decidir,

${ }^{(13)}$ Maria O’Neil, “O Meu Feminismo", Pensamento, n. ${ }^{\circ} 4$, Jun. 1930, p. 84.

(14) Nídia Neto Ferreira, "Feminismo", Pensamento, n. ${ }^{\circ}$ 8, Nov. 1930, p. 185.

(15) Leopoldina Mesquita, "A Função Social da Mulher", Pensamento, n. ${ }^{\circ} 56$, Jan. 1935, p. 5.

(16) Maria Clara Ferreira Alves, "O Feminismo", Pensamento, n. ${ }^{\circ}$ 5, Ago. 1930, p. 107. 
a segunda agir como ser humano autónomo consciente e responsável. E já que, segundo várias opiniões, teria sido a dependência económica a ditar a subalternização pessoal, o acesso ao mundo do trabalho e a retribuições salariais adequadas, apresentavam-se como condições essenciais à emancipação da mulher e, daí, à sua "dignidade e liberdade, tão essenciais à felicidade humana"(17), como se dizia.

Embora estas feministas recorressem frequentemente ao exemplo masculino, estavam longe de pretender "fazer da mulher uma ridícula contrafaç̧ão do homem" como bem afirmava Clara Ferreira Alves ${ }^{(18)}$. Tendo perfeita consciência do que igualava homens e mulheres enquanto seres humanos, apostavam na identidade específica do masculino e do feminino, dentro da categoria universal. Por isso, para elas, o "feminismo era uma doutrina feminina" ${ }^{19)}$, e pretendiam como consequência que "os homens fiquem homens, e as mulheres, mulheres"(20), ou, por outras palavras, "queriam um homem e uma mulher que soubesse sê-lo"(21). Pensar o contrário, querer masculinizar a mulher seria uma clara afirmação de menoridade, incompatível com a noção do que se entendia por ser mulher. Nesta perspectiva, afirmar que a mulher se queria e devia ser "inteiramente" feminina significava que, embora com diferenças específicas em relação ao homem, era sua igual quanto aos direitos humanos, e como tal devia ser respeitada.

Esta distinção afastava a ideia de igualdade como igualização, e acolhia e ideia de diferença, fazendo do binómio igualdade/diferença o critério por excelência para caracterizar o feminismo tal como era concebido pelas feministas da Pensamento. Aplicado com incidências e, sobretudo, com graus diversos, serviu para legitimar a feição socialista do feminismo e, ao mesmo tempo, para censurar quem acentuasse o valor da diferença, esquecendo ou subestimando a igualdade essencial dos seres humanos. As páginas da revista em análise encerram um exemplo desta realidade ao inserirem a polémica desencadeada pela publicação de um artigo de

(17) Idem, p. 106.

(18) Idem, pp. 106-107.

(19) Elina Guimarães, "O que se deve entender por feminismo", Pensamento, n. ${ }^{\circ}$, Out. 1930, p. 153.

(20) Maria Clara Ferreira Alves, cit., p. 106.

${ }^{(21)}$ Maria O'Neil, cit., p. 83. 
Dinah Santos Silva, intitulado $A$ igualdade sob todos os pontos de vista não traz a felicidade, assim como a declaração expressa da autora negando a sua filiação socialista ${ }^{(22)}$. Seja como for, as feministas da Pensamento consagraram a essencialidade da igualdade e da diferença para fundamentar teoricamente a emancipação e dignificação da mulher, e legitimar o feminismo enquanto acção concertada para o promover. Posicionavam-se, pois, como intelectuais e longe de formularem propostas de acção concreta e imediata no modo de viver quotidiano. Mantinham-se, sim, nos parâmetros do que seria um feminismo doutrinário.

A abordagem da "questão feminista" veiculada por O Diabo apresentava um cariz um tanto ou quanto diferente, se não no campo conceptual, pelo menos no formal. O facto de ter promovido o já mencionado Inquérito às Mulheres Portuguesas, no segundo ano da sua existência e de ter publicado as respostas com brevidade e continuidade, a acuidade $e$ pertinência das questões postas e o interesse claramente manifestado de "procurar os melhores nomes da intelectualidade portuguesa"(23) para lhes dar resposta, configura sensibilidade semelhante à da Pensamento quanto à "questão feminina" na nova sociedade que se pretendia culta $e$ na qual os intelectuais marcariam a sua presença. Parece, porém, poder vislumbrar-se uma diferença face ao exemplo anterior e também ao de Ana de Castro Osório. Ambos veicularam um "feminismo feminino", isto é, entregavam às mulheres a defesa dos seus direitos, pois julgavam ser a elas que competia enunciá-los e lutar por eles. Agora, com O Diabo desenhavam-se os contornos de um "feminismo masculino" de forma que hoje se afigura evidente. Eram os homens que escreviam sobre as mulheres, sem dúvida em sua defesa, mas evidenciando um certo paternalismo ou proteccionismo. Aliás, as palavras de apreciação das respostas correspondem lapidarmente a esta forma de pensar:

(22) Veja-se sobre este assunto Zília Osório de Castro, "Paridade cultural", in Falar de Mulheres. Da igualdade à paridade, Lisboa, Livros Horizonte, 2003, p. 290.

(23) "Inquérito às Mulheres Portuguesas. As aspirações da mulher e o amor na sociedade actual - $O$ ciclo histórico em que a mulher foi mais feliz - A influência da Maternidade na vida da mulher", O Diabo. Grande Semanário de Literatura $e$ Crítica, n. ${ }^{\circ} 69,26$ Out. 1935, p. 1 . Sobre este periódico veja-se a dissertação de mestrado apresentada à FCSAH/UNL em 2001, por Luís Trindade, $O$ espírito do diabo. Discursos e posições intelectuais do semanário "O Diabo", 1934-1940. 
“O Diabo, não deixará contudo, de em duas palavras, dizer um pouco do muito que pensa a propósito da situação da mulher portuguesa. Se esta ainda hoje é um reflexo da intelectualidade masculina, desculpável é que a sua mentalidade sofra algumas vezes os efeitos da influência do homem. O que se torna necessário, pois é que o homem se dignifique, elevando a mulher, não a considerando um ser subalterno, à margem da sua actividade intelectual e apregoada superioridade tantas vezes desmentida"(24).

Repare-se na "desculpabilização" da subalternidade da mulher portuguesa e, sobretudo, nas palavras que se lhe seguem-é preciso, pois, que o homem se dignifique, elevando a mulher. Como é evidente, um fosso separava, neste aspecto, o "feminismo masculino" do "feminismo feminino". Ambos procuravam a dignificação da mulher, mas este entendia-a como resultado de combate pessoal, e aquele como reflexo da dignificação dos homens. Neste caso, a menoridade feminina mantinha-se sob a capa de uma pseudo maioridade. De assinalar, porém, que tanto nas páginas da Pensamento como nas de O Diabo, nem o feminismo se circunscreve liminarmente às mulheres, nem a "questão feminista" é apenas um problema exclusivo de mulheres. Envolve e reflecte-se na sociedade total, porque se inscreve numa perspectiva social e cívica da realidade, partilhada por ambos os periódicos, embora, com incidências diversas nos enunciados.

É legítimo perguntar, sem pôr em causa as virtualidades do referido Inquérito, quem teria sido o autor ou a autora e se se inseria, também ele ou ela, na linha do "feminismo masculino". Este era, aliás, uma realidade no panorama cultural e intelectual da segunda fase do feminismo português e o Sol Nascente seria um dos mais lídimos representantes. Um artigo ali publicado e intitulado "As Raparigas nas Universidades Portuguesas" é um expoente significativo dessa conceptualização. O autor, André Valmar, depois de afirmar que "as raparigas chegam às universidades com os olhos vendados e os seus dezoito anos cheios de inexperiência", entregava aos rapazes a responsabilidade de pôr cobro à situação e de incentivar as raparigas a aderirem "à causa da cultura"(25).

\footnotetext{
(24) “N. da R.", O Diabo..., n. ${ }^{\circ} 85,9$ Fev. 1936, p. 7.

(25) André Valmar, "As Raparigas nas Universidades Portuguesas", Sol Nascente, n. ${ }^{\circ} 42,15$ Jan. 1940, p. 7. André Valmar pseudónimo de António José Castro, que viria a ser engenheiro na Marinha Grande.
} 
"É preciso - dizia - que [...], aproveitando a convivência que têm com as suas companheiras de estudo [...] se esforcem por lhes abrir os olhos, por lhes iluminar os espíritos, por as tornar melhores, mais perfeitas, mais humanas" (26). Para concretizar este objectivo, traçou um programa completo de acção em que os rapazes seriam os grandes mentores da formação intelectual das raparigas. Pertencia-lhes "dar-lhes a verdadeira consciência do sexo [...] fazer-lhes conhecer e admirar as obras de mulheres prestigiadas [...] estimular-lhes o gosto pelas exposições de arte, por concertos musicais e por conferências de carácter educativo $[\ldots]$ indicar-lhes os poucos bons filmes que vêm encalhar nas nossas salas [...] inscrevê-las em clubes desportivos femininos , estabelecer como base das relações entre rapazes e raparigas a camaradagem, a lealdade, a confiança mútua e a amizade $[\ldots]^{\prime \prime}(27)$.

Este excessivo paternalismo levantou os mais veementes protestos consignados em carta dirigida a André Valmar por Etelvina Lopes de Almeida e que, sem dúvida, exprimia sentimentos bem mais generalizados. E porquê? Porque, nas palavras desta feminista, os rapazes de então, manifestavam um modo de pensar retrógrado e tradicionalista e, por isso, não eram "dignos guias para desbravar terreno"(28). E perguntava: "quantos conhece V. capazes da missão que lhes destinou no seu artigo?"(29), enumerando a par e passo a incompetência masculina nos diversos pontos que ele enunciara. Ao contrário do que ele aconselhava, a libertação da mulher de "caducos preconceitos", implicaria, no seu entender, a criação de "novos moldes de vida", resultantes da acção comum de homens e de mulheres. "É preciso que a mulher se liberte, mas que o homem saiba compreender tal liberdade"(30) - dizia. O desafio da cidade nova era para ambos, porque decorrente na sua efectivação de acção conjunta. O feminismo de Etelvina Lopes de Almeida conjugava as conquistas alcançadas ou a alcançar num projecto de futuro, feito de

(26) Idem, ibidem.
${ }^{(27)}$ Idem, ibidem.
${ }^{(28)}$ Carta autógrafa inédita de Virgínia Lopes de Almeida, datada do Monte da Caparica a 14 de Fevereiro de 1940 e dirigida ao "Ex. mo Senhor Director de Sol Nascente". Agradeço vivamente ao meu colega e amigo Luís Crespo de Andrade, ter-me facultado este documento.

(29) Idem, ibidem.

(30) Idem, ibidem. 
relacionamento paritário, de conjugação de esforços no sentido de dignificação do ser humano na plenitude das suas capacidades intelectuais, reflectidas na intervenção cívica de cada um. Portanto, nada de paternalismos, mas também nada de individualismos. E, neste sentido, fosse de quem fosse a iniciativa do Inquérito realizado por O Diabo, o "feminismo masculino" veiculado não era uma excepção entre os intelectuais portugueses. E, além disso, segundo Etelvina Lopes de Almeida, na sua exclusividade, era tão pernicioso como o idêntico "feminismo feminino". Uma terceira forma de pensar estava patente na sua resposta que, sem negar as características próprias do feminismo de intervenção e de participação, traçava um outro caminho que unia mulheres e homens no objectivo comum de construir a cidade nova.

Regressando à análise do Inquérito, importa salientar elementos favoráveis a qualquer tentativa de conceptualização do feminismo, indispensável à análise da sua conjugação com o movimento intelectual do período em apreço. Um deles consiste em ter veiculado opiniões de mulheres de diversos quadrantes da sociedade portuguesa: escritoras, actrizes, professoras, médicas, operárias, estudantes, desfilam perante os nossos olhos dando vida às suas declarações. O outro é a disparidade de pontos de vista quanto ao que cada uma pensa da condição da mulher e da sua integração na sociedade, e também do feminismo e da intelectualidade feminina. $O$ último traduz-se no espírito crítico que, por vezes, transparece das respostas.

Assim, as reticências à ideia de ser possível a existência de uma nova mulher, paladina da igualdade, da liberdade e do trabalho são pelo menos dignas da maior reflexão. A escritora Mercedes Blasco, por exemplo, considerava irredutível a condição da mulher no mundo - "a mulher há-de ser sempre escrava do homem"(31) - e, ao falar da nova mulher, da mulher moderna, chamava-lhe hipócrita e artificial. Por perto, nas referências à mesma questão, andam outras escritoras, como Maria Archer, Aurora Aranha e Ludovina Ferreira Neto, e mesmo Maria Lamas não deixa de afirmar com um certo cinismo: "Existe realmente uma categoria de 'Novas Mulheres', a das mulheres em série conforme o último modelo de Hollywood. No íntimo, salvo as excepções, a Mulher

${ }^{(31)}$ Mercedes Blasco, "Fala a escritora Mercedes Blasco", Inquérito às Mulheres Portuguesas, O Diabo, n. ${ }^{\circ}$ 71, 3 Nov. 1935, p. 1. 
será sempre a mesma. Aparece, é bem verdade, uma ou outra Mulher com nova concepção de vida. Mas são tão poucas..."(32).

É evidente que a subestimação da mulher nos moldes acabados de referir trazia consigo a desvalorização do feminismo enquanto movimento emancipador e libertador da mulher. Tendo em conta esta problemática, tal como $O$ Diabo a veiculou, evidenciam-se pelas suas posições extremas, embora de sinal oposto, as opiniões de Elina Guimarães e de Maria Lamas. A primeira considerava o feminismo como a expressão da tomada de consciência da missão cultural da mulher que esta assumia ou em casa no desempenho, de tarefas domésticas, ou, se necessário, fora de casa, ocupada em trabalhos afins, como o ensino ou a assistência social, cooperando, deste modo, ao lado do homem, na construção da cidade nova ${ }^{(33)}$. Neste sentido, o feminismo reconhecia o papel tradicional da mulher, e conjugava-o com a sua inserção social. A segunda emitiu, mais uma vez, uma opinião que primava pelo inesperado e que não deixava de ser devastadora. Afirmava ela, respondendo à questão que lhe tinha sido posta. "De um modo geral estou fora do problema do feminismo porque não o compreendo nem o sinto como a maioria das mulheres. Não me interessa, por exemplo, a luta pelos direitos políticos. Fala-se também muito em erros e deficiências da ordem pública. É certo. Mas reconheço, contudo, que a maioria das mulheres portuguesas não possui uma personalidade para merecer a igualdade com os homens perante a lei"(34). Lateja aqui a recusa da nova cidade através da recusa de intervenção, nomeadamente na esfera política, e daí a recusa da nova mulher. Não admira que o feminismo tal como era entendido nas duas publicações em análise nada lhe dissesse e que nem a questão da igualdade lhe merecesse mais que uma simples rejeição.

Apostar no feminismo significava acreditar na existência possível de uma nova mulher, convicta da sua missão no mundo ${ }^{(35)}$, independente e culta, embora sem necessariamente abandonar os paradigmas ancestrais.

(32) Maria Lamas, "Fala a escritora Maria Lamas ", Inquérito..., cit., in O Diabo, n. ${ }^{\circ} 87,25$ Fev. 1936, p. 4.

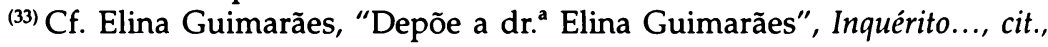
in O Diabo, n. ${ }^{\circ} 87,25$ Fev. 1936, p. 5.

(34) Maria Lamas, cit.

(35) Veja-se Manuela Palma Carlos, "Depõe a dr. a Manuela Palma Carlos", Inquérito..., cit., in O Diabo, n. ${ }^{\circ} 85,2$ Fev. 1936, p. 7. 
Implicava o desejo de independência, de colaboração, de conquista de direitos, de trabalho, de realização pessoal. Traduzia-se no incentivo para a valorização pessoal, para a emancipação, para a conquista da dignidade de pessoa humana, para a plenitude intelectual, numa palavra, para a "criação" de uma nova mulher, inseparável da construção de uma nova sociedade. Conceptualmente, a nova mulher enforma o paradigma moderado da Elina Guimarães:

"A mulher verdadeiramente moderna é aquela que concilia a doçura de sempre com a erudição de hoje. Moderna é essa encantadora Irene Curie, detentora do Prémio Nobel, que sabe ser uma sábia eminente, esposa dedicadíssima, colaboradora do marido, mãe carinhosa e mulher sempre distinta e elegante. Modernas são essas raparigas que estudam e trabalham como homens, mas que permanecem mulheres na bondade $e$ no sacrifício"(36)

E informa igualmente o paradigma radical do Sol Nascente, no espaço bastante reduzido que dedicou à temática do feminismo. Todavia a nova mulher era ali descrita como a mulher que trabalha, que alimenta a inteligência, que se interessa pela cultura, cooperando na descoberta de novos ideais. Era a mulher que conquistava a autonomia, "que arranca a independência do seu trabalho, pensa com o seu cérebro, que se traçou uma conduta consciente [...], actuando numa liberdade difícil a querer com a sua vontade"(37). Numa palavra, a mulher nova era um ser social como o homem, isto é, um ser dotado de capacidade para intervir na sociedade em que vivia, e que se realizava, desenvolvendo as suas potencialidades onde quer que se encontrasse. Na sua essencialidade, a mulher nova nada tinha com o passado, pois o que verdadeiramente a caracterizava eram as suas virtualidades e a possibilidade do seu exercício.

Apesar dos diferentes modos de pensar acabados de referir e das divergências abissais reflectidas nas respostas das entrevistadas de O Diabo, num ponto estavam implícita ou explicitamente de acordo. Apoiavam quase sem reservas o desenvolvimento cultural da mulher, sem que houvesse unanimidade nem nas razões apresentadas para $o$

(36) Elina Guimarães, cit.

(37) Mando Martins, "Novo tipo de mulher de Júlio Dantas e a nova. mulher", Sol Nascente, n. ${ }^{\circ}$, 1 Jun. 1937, p. 13. Mando Martins, pseudónimo de Armando Martins Janeira que viria a seguir a carreira diplomática. 
justificar, nem nas suas incidências. Paradigmáticas deste último aspecto eram as diferentes concepções de nova mulher acabadas de referir, e o que elas implicavam como expressão de um modo de ser e de estar. Significativas do primeiro contavam-se as discrepâncias na argumentação expendida e o seu significado como expoentes de mentalidade, partilhadas ou, pelo menos indiciadas, pelo próprio periódico. A aliança entre os putativos benefícios do desenvolvimento intelectual da mulher e as suas incidências na vida familiar, presente por vezes na formulação das questões, não reflectia uma certa intencionalidade? Por outro lado, as reservas formuladas ao longo das entrevistas foram escassas, indecisas e pouco fundamentadas.

Ultrapassando o impasse que conduziria a uma mera especulação sobre as questões acabadas de formular, importa analisar as ideias enunciadas, tanto na globalidade uniformizante, como nos particularismos identificadores de modos de pensar específicos dentro do universo comum. Num caso e noutro, salienta-se a interligação entre intelectualidade e feminismo, já que, se por um lado subjaz a concepção de nova mulher acima referida, por outro pressupõe a integração da mulher no círculo dos intelectuais e das suas propostas de uma nova sociedade, como se tem acentuado. Ora, a nova sociedade, tal como era apresentada neste contexto, implicava sempre a dignificação intelectual da mulher e, por vezes, a partir desta, a valorização da vida familiar, como condições essenciais à sua construção. Promover o desenvolvimento intelectual equivalia a um processo de libertação, já que, como se dizia, "a ignorância deprime e escraviza" a "cultura desenvolve a inteligência e emancipa o pensamento"(38). E equivalia igualmente a horizontes de felicidade - "a mulher culta tem mais probabilidades de ser feliz" - e da perfeição decorrente "de uma evolução e de um progresso"(39), de "consciente preparação para a vida"(40), assim como de "melhor conhecimento desta"(41),

(38) Anémona Adelaide Xavier de Basto, "Fala a professora Anémona Adelaide Xavier de Basto", Inquérito... cit., in O Diabo, n. ${ }^{\circ} 84,2$ Fev. 1936, p. 7.

(39) Maria Luiza Palma Carlos, "Fala Maria Luiza Palma Carlos, da Faculdade de Medicina", Inquérito..., cit., in O Diabo, n. ${ }^{\circ} 82,18$ Jan. 1936, p. 3.

(40) Aurora Jardim Aranha, "Fala a escritora Aurora Jardim Aranha", Inquérito..., cit., in O Diabo, n. ${ }^{\circ} 69,6$ Out. 1935, p. 1.

${ }^{(41)}$ Maria Lamas, cit. 
da criação da "sua verdadeira personalidade"(42), de "interesses próprios"(43) e, enfim, de "dignificação"(44) e de "necessidade de abrir novos horizontes no seu espírito"(45).

Perpassa nas ideias expostas a noção de cultura como índice de enriquecimento individual e, daí, na vida do dia a dia. A cultura, tornavase, portanto, imprescindível à concepção de mulher como ser dotado de valor próprio decorrente da dignidade que lhe advinha da assunção da sua personalidade pensante e actuante. Só pela cultura a mulher encontrava a plenitude da sua condição de mulher, porque a tornava consciente das suas infindas virtualidades de ser humano, e que deviam informar a sua vivência. Vivência, por vezes entendida como exclusivamente pessoal, mas também encarada primordialmente nas suas incidências familiares, isto é, nas relações que a mulher estabelecia com o marido e os filhos. Em palavras precisas Manuela Palma Carlos expôs o seu modo de encarar esta questão: "Cultivando o seu espírito a mulher está sempre apta para ser a colaboradora do marido, a colaboradora dos seus trabalhos e a primeira do seus admiradores. Junto dos filhos o seu papel será ainda mais importante - porque ninguém melhor que a Mãe poderá orientá-los na sua educação" (46).

Nesta afirmação o pendor tradicional da imagem da mulher correspondente à inserção na esfera familiar conjugava-se com a inovação ditada pela "aplicação" dos valores culturais adquiridos ao bem estar e felicidade da familia. A mulher era apresentada como colaboradora do marido e educadora dos filhos porque desenvolvera as capacidades para o ser. O papel da cultura na esfera da acção da mulher conferia-lhe uma outra dignidade que, sem anular a tradição, a conjugava com a inovação. Este modo de ver, que hoje se afigura primar pela moderação ditada por

${ }^{(42)}$ Heloísa Cid, "Fala Heloísa Cid", Inquérito..., cit., in O Dia, n. 72, 10 Nov. 1935, p. 1.

${ }^{(43)}$ Elina Guimarães, cit.

(44) Marta de Mesquita Câmara, "Resposta a um inquérito de 'O Diabo'”, in O Diabo, n. ${ }^{\circ} 87,25$ Fev. 1936, p. 5.

${ }^{(45)}$ Maria Letícia Clemente da Silva, "Depõe Maria Letícia Clemente da Silva", Inquérito..., cit., in O Diabo, n. ${ }^{\circ} 82,18$ Jan. 1936, p. 3.

(46) Manuela Palma Carlos, cit. Veja-se, sobre este assunto, Tereza Pinto, "Instrução e feminidade: pluralidade dos discursos em finais de oitocentos", Falar de Mulheres..., cit., pp. 261-278. 
excessiva contemporização com a permanência de modos de estar nunca criticados, era afinal expressão de um certo protagonismo, se não, de progressismo. Significativo do distanciamento face a uma outra mentalidade era o modo de pensar segundo o qual "não seria preciso ser intelectual para ser boa dona de casa, o que não queria dizer que uma intelectual não possa ser isso tudo"(47). Se bem que neste caso se subvalorize o factor intelectual, noutros o temor que ele ofusque a afectividade, considerada para alguns a característica essencial da mulher, perpassa nalgumas intervenções. As palavras mais contundentes neste aspecto foram as de Maria Archer, quando se referiu ao desenvolvimento intelectual da mulher: "De princípio é um mal, porque a mulher por seu intermédio perde a faculdade de admirar os homens. Em relação ao lar, esses efeitos são mínimos: o lar é campo mais próprio para manifestações afectivas do que para manifestações intelectuais"(48).

Se bem que estas palavras não colhessem unanimidade de aplausos, a questão da afectividade e da sua equação com a intelectualidade sobressai por vezes. Indicia preocupação latente, embora superada pela proposta da conjugação de ambas, no sentido positivo de que " mulher inteligente se deve voltar para o lar, tornando-o belo e doce"(49) e consciencializando as relações afectivas ${ }^{(50)}$. Pernicioso seria se devido ao progresso intelectual a mulher perdesse "a sua personalidade e a sua espiritualidade feminina"(51). A distinção entre as identidades feminina e masculina que estas palavras traduzem, e sobretudo o apelo a uma intelectualidade feminina distinta da masculina, são elucidativas quanto à adequação ideológica do binómio igualdade/diferença e teórica dos princípios fundamentadores das declarações de direitos, aliás aglutinadora de todas as formas de feminismo. A consciência de que o desenvolvimento intelectual, embora fosse um bem, pudesse tornar-se perverso para os ideais feministas professados, traduziu-se na evocação do pensamento

(47) Ludovina Frias de Matos, "Fala a escritora Ludovina Frias de Matos", Inquérito..., cit., in O Diabo, n. ${ }^{\circ} 76,8$ Dez. 1935, p. 4.

${ }^{(48)}$ Maria Archer, "Fala a escritora Maria Archer", Inquérito..., cit., in O Diabo, n. ${ }^{\circ}$ 71, 3 Nov. 1935, p. 1.

(49) Maria Lamas, cit.

(50) Emília Araújo Pereira, "Fala Emília Araújo Pereira", Inquérito..., cit., in O Diabo, n. ${ }^{\circ} 72,10$ Nov. 1935, p. 1.

${ }^{(51)}$ Maria Lamas, cit. 
de Rousseau: "Cultiver dans les femmes des qualités de l'homme et négliger celles que leur sont propres, c'est donc visiblement travailler à leur préjudice..."(52).

As incidências individuais e familiares da promoção intelectual da mulher projectavam-se na sociedade e na humanidade. "Perante a sociedade a mulher culta será sempre um elemento de valor porque trabalha para o progresso e para a perfeição humana"(53) - dizia-se. Cabia-lhe, assim, um vasto campo de aç̧ão derivado da responsabilidade e interesse pela "vida colectiva", e que se manifestava ou de forma directa, dando especial atenção aos pobres e às crianças ${ }^{(54)} e$ empenhando-se em minorar a situação das mulheres que vivessem "na servidão e no sacrifício"(55). Nesta perspectiva, a construção da nova sociedade passava pelo contributo indispensável das mulheres intelectuais e pela sua "sensibilidade feminina, muito feminina"(56). Com a sua intervenção seria possível "elevar o nível intelectual da humanidade" ${ }^{\prime(57)}$, construir uma nova era de felicidade"(58), realizar "o máximo possível de sonhos e ansiedades"(59). Enfim, podia dizer-se que "a mulher inteligente e culta é um valor social equivalente a uma esperança em melhores dias para a vida da Humanidade"(60).

Nesta perspectiva como mulher nova cumpria a sua missão na construção da cidade nova, pelo simples facto de estar como intelectual na sociedade, ou seja, de aproveitar as potencialidades do seu ser humano feminino. Neste processo, ao feminismo enquanto movimento cultural cabia o lugar de chegada das aspirações realizadas, e de ponto de partida para novas realizações, isto é, identificava-se com a vida vivida das mulheres e com o fluir das sociedades.

Em resumo. A acção doutrinadora de $O$ Diabo conjugava-se com a da Pensamento e trazia à colação o contributo de Ana de Castro Osório, no sentido de salientar o contributo das intelectuais na construção da

\footnotetext{
(52) Citado por Marta Mesquita Câmara, cit.

${ }^{(53)}$ Maria Letícia Clemente da Silva, cit.

(54) Maria Luiza Palma Carlos, cit.

(55) Manuela Palma Carlos, cit.

(56) Maria Letícia Clemente da Silva, cit.

(57) Maria Lamas, cit.

${ }^{(58)}$ Maria Letícia Clemente da Silva, cit.

(59) Elina Guimarães, cit.

${ }^{(60)}$ Raquel Bastos, cit.
} 
sociedade do futuro. E o feminismo, enquanto movimento cultural de feição individual feminina em Ana de Castro Osório, social feminina na Pensamento, e social masculina em $O$ Diabo, foi a sua expressão através do pensamento e acção das feministas intelectuais, quer estas tenham sido ou não suas colaboradoras. 